\title{
Pott's paresis presentation in the emergency department
}

\author{
Charles Ochello Jr.・ Lisa D. Mills
}

Received: 17 January 2008 / Accepted: 7 February 2008 / Published online: 19 March 2008

(C) Springer-Verlag London Ltd 2008

A 41-year-old man presented with lower extremity weakness and numbness that began $48 \mathrm{~h}$ prior to presentation. He noted progressive difficulty in ambulation, numbness and tingling from the lower abdomen to the toes, and difficulty initiating urination. He had been diagnosed with pulmonary and spinal tuberculosis 8 weeks previously after presenting with upper back pain after a mechanical fall and was undergoing anti-tuberculosis medical therapy. At the time of initial diagnosis he had pulmonary and T6-T7 bone involvement, but no epidural involvement. He was compliant with drug therapy and had documented negative sputum tests after 2 weeks of treatment.

Vitals signs upon presentation were: pulse 110 beats/ min, respiratory rate 18 breaths $/ \mathrm{min}$, blood pressure $112 /$ $78 \mathrm{mmHg}$, and temperature $36.4^{\circ} \mathrm{C}$. Physical exam demonstrated tenderness in the T5-T7 area. On neurological

Presented at the 4th Mediterranean Emergency Medicine Congress, Sorrento, Italy, September 2007.

C. Ochello Jr. $(\bowtie)$

Department of Surgery, Division of Emergency Medicine,

Duke University Medical Center,

DUMC 3935, Erwin Road, Duke North, Room 0681,

Durham, NC 27710, USA

e-mail: charles.ochello@duke.edu

L. D. Mills

Department of Internal Medicine, Section of Emergency Medicine

Louisiana State University at New Orleans,

New Orleans, LA, USA exam, sensation was intact to light touch above approximately the T5 sensory level, and numbness was present below the T5 sensory level bilaterally. Strength was $5 / 5$ in the upper extremities and $4 / 5$ in the lower extremities. DTRs in the lower extremities were $1+$ bilaterally. The toes were down going bilaterally, and toe proprioception was intact bilaterally. Heel-to-shin test was unable to be completed by the patient. The patient could only ambulate with assistance due to lack of coordination. A rectal exam performed noted normal rectal tone. MRI was obtained and demonstrated gross abnormalities of T5-T6 and multiple epidural abscesses in the T5-T6 region, causing displacement of the spinal cord posteriorly (Fig. 1).

The most common cause of delay in the diagnosis of bony tuberculosis is failure to consider the diagnosis, especially in patients who have normal chest radiographs. More than $50 \%$ of such patients do not have evidence of active chest disease [1]. Among patients that manifest bony tuberculosis, the spine is involved in $50 \%$ of patients. Of those involving the spine, the thoracic spine is the site of infection in $50 \%$, the cervical spine in $25 \%$, and the lumbar spine in $25 \%[2,3]$. Like tubercular infection of the spine, epidural abscess is commonly misdiagnosed as a benign cause of back pain. Most epidural abscesses are not diagnosed until the patient has neurologic deficits or a fever [4]. In any mass effect on the spine, neurosurgical consultation should be obtained, emergently. Empiric therapy for active TB infections is multi-drug therapy. Treatment is continued for at least 6 months. 


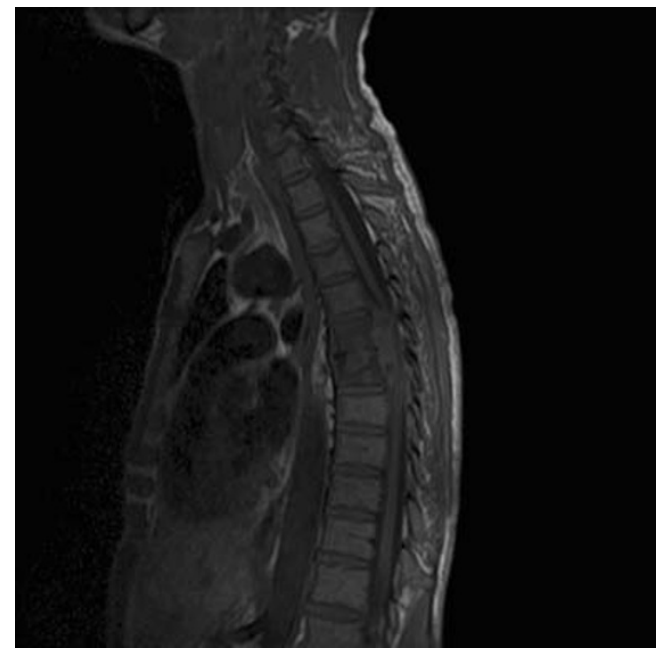

\section{References}

1. Davidson PT, Horowitz I (1970) Skeletal tuberculosis. A review with patient presentations and discussion. Am J Med 48:77

2. Centers for Disease Control: Summary of notifiable diseases, United States. 1991. Morbid. and Mortal. Weekly Rep. 1992; 41:1-63

3. Bloch AB, Rieder HL, Kelly GD et al (1989) The epidemiology of tuberculosis in the United States. Sem Respir Infect 4:157-170

4. Rigamonti D, Liem L, Worf AL et al (1962) Epidural abscess in the cervical spine. Mt Sinai J Med 61(4):357-362
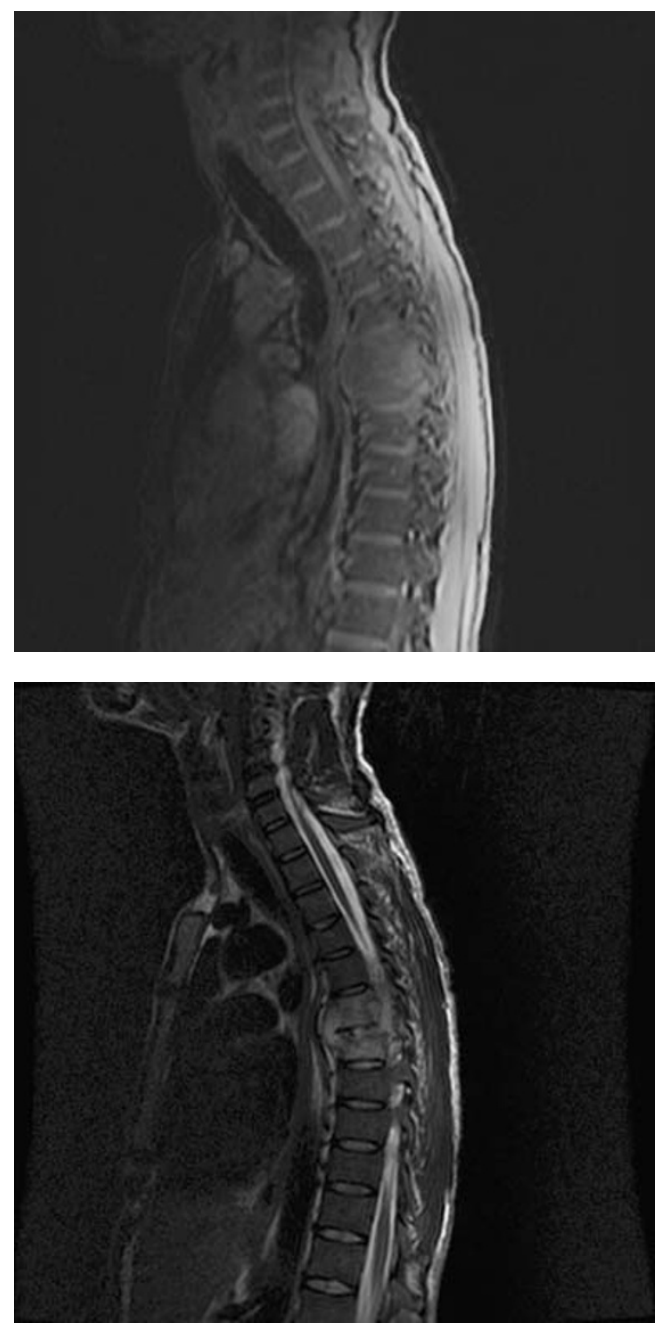

Fig. 1 Magnetic resonance imaging at presentation demonstrated multiple epidural abscesses in the T5-T6 region with enhancing paravertebral masses bilaterally and an enhancing epidural mass. The epidural mass caused displacement of the spinal cord posteriorly. 